Arqueología y Sociedad,

№ 22, 2010

\title{
CANAles, ABASTECIMIENTO DE AGUA Y SISTEMAS DE IRRIGACIÓN EN LIMA: EL CASO DEL CANAL HuATICA
}

\author{
Paul Pérez Chávez*
}

\section{Resumen}

En el presente artículo trataremos de dar cuenta de las consecuencias que el abastecimiento de agua y las irrigaciones en el río Rímac — específicamente, en su margen izquierda - produjeron en la nueva sociedad que se instalaba luego de la Conquista. Además, desarrollaremos las características de los sistemas de abastecimiento de agua potable que fueron utilizados en la Lima colonial, así como los sistemas de regadío, enfocándonos en uno, en particular, denominado Huatica. Dicho canal, de origen prehispánico, nos permitirá finalmente tener una visión de la evolución de la utilización del agua para regadío, del aprovechamiento económico al que fue sometida y del uso para la limpieza e higiene de la ciudad como elemento de los primigenios desagües de la ciudad.

Palabras clave

Rímac, Huatica, canal, río, abastecimiento, agua.

\begin{abstract}
The aim of this article is to explain how water supply and the irrigations on the left bank of the Rímac River produced in the new society who settled after the Conquest. Besides, we will develop some water supply features, used in Colonial Times and finally we will talk about an important irrigation canal called Huatica. This canal, built in Pre-hispanic times, will give us a clear idea of the development regarding water use for irrigation, the economic exploitation to which it was subjected and its use for the cleanliness and hygiene of the city and its importance as an element of the original draining system in Lima.
\end{abstract}

Keywords

Rímac, Huatica, canal, river, supply, water.

* Bachiller en Arqueología de la Universidad Nacional Mayor de San Marcos.

Correo electrónico: gua1840@hotmail.com 
La ciudad de Lima se encuentra ubicada en el sector central y occidental del Perú, país en el que es posible distinguir espacios geográficos como el litoral, el área desértica, los valles y el sector andino. Desde el punto de vista geológi$\mathrm{co}$, su territorio se caracteriza por la presencia de franjas relacionadas con la formación correspondiente y se encuentran depósitos sedimentarios. Presenta también un área desértica que mide solo 10 kilómetros, a diferencia de otras regiones costeras.

Con respecto a los valles, se puede afirmar que han sido modelados por la acción erosiva de los ríos Chillón, Lurín y Rímac, todos ellos con caudal anual variable. El objeto de estudio del presente trabajo es este último - cuyo afluente es el Santa Eulalia-, cuyas derivaciones en acequias dan paso al aprovechamiento de sus aguas que se trasladan a los campos de cultivo. El valle que origina dicho río recién se amplía a partir de Surco y es en Vitarte donde empieza su llanura, que llega hasta los 30 kilómetros de ancho al momento de desembocar en el océano Pacífico, a la altura del Callao (PEISA 2004, 10).

\section{Los INICIOS}

Las poblaciones en la Lima prehispánica, mediante la adecuación progresiva de distintas técnicas, produjeron una serie de transformaciones sociales que se derivaron en una mejor aplicación de esas técnicas, así como en un uso equilibrado y una correcta preservación de las tierras de cultivo. Además, haciendo uso de la observación y el análisis, pudieron evaluar cómo controlar los flujos de agua, establecer los puntos de captación y, sobre todo, ejecutar el traslado de las aguas desde esos lugares hasta los sistemas de cultivo; así, por ejemplo, por ensayo y error, constataron al inicio que podían realizar esta última actividad realizando un simple surco en la tierra.

Una de las primeras sociedades que ejecutaron la construcción de canales fue Chavín y puede aseverarse que sus pobladores tuvieron conocimiento de la energía de velocidad del flujo. La agricultura en Chavín se presentó en la forma llamada establecida, es decir, poseyendo ya los fundamentos de un tipo superior. Se conocía el riego y se usaban las prácticas religiosas agrícolas como un elemento principal de la economía, figurando el maíz en forma preponderante (Regal 2005, 28). En efecto, se ha demostrado que conocieron las causas de erosión, la mecánica de filtración, el control de flujo vertiente, entre otros.

El ambiente en que vivieron los antiguos pobladores de Lima fue decisivo para su desarrollo. Se entiende que el medio ecológico fue equilibrado y que el manejo de la biodiversidad y de su defensa se convirtió en una práctica diaria y común. Ellos desarrollaron la actividad agrícola en las áreas menos susceptibles de ser destruidas y utilizaron para ello una variedad de sistemas, con lo cual obtuvieron miles de hectáreas para una agricultura extensiva.

\section{TéCNICAS DE CONSTRUCCIÓN DE CANALES}

Para la construcción de canales es menester conocer previamente algunas variables: volumen de agua, probable longitud del canal, ubicación del punto o los puntos de captación y de entrega, extensión y condiciones o composición de los suelos de regadío, características del terreno del trazado del canal, datos climáticos y naturaleza fisiográfica de la zona, fuerza laboral requerida y tipo de canal (Deza 2005, 135).

\section{Partes de un canal}

Además, los canales presentan características similares según sus partes constituyentes, como lo expone Deza $(2005,142)$ :

Bocatoma: Punto de captación, ubicado en un lugar escogido, desde donde se desvía el cauce del río o se deriva el agua de la laguna o lago. Para que dicho sistema funcione, se requiere conocer la longitud que tendrá el canal, así como también la profundidad del río.

Canal madre o principal: Canal principal, que empieza desde el punto de captación o boca- 
toma y reparte su caudal a los canales secundarios.

Canales secundarios o de derivación: Canales que reciben agua del canal madre y la conducen hacia los campos de cultivos.

Compuertas: Estructuras de retención y derivación del agua.

Canales de desagüe: Canales que derivan el agua del canal principal para evitar posibles desbordes.

Acueducto: Conducto artificial elevado para transportar el agua y cruzar depresiones pronunciadas o quebradas, manteniendo el nivel del canal.

\section{IMPORTANCIA DEL AGUA}

Desde tiempos antiguos, el agua no solo fue vista como un mero recurso para el regadío de cultivos, sino también como un eje de ordenamiento étnico en los valles (Rostworowski 1978, 51). Así pues, basándose en las crónicas, la autora en referencia ubica a curacazgos y señoríos asentados antes de la llegada de los españoles en el territorio de lo que hoy conocemos como Lima Metropolitana. Por otro lado, se ha encontrado que existe una relación entre las conexiones hidráulicas subterráneas y los antepasados; así, por ejemplo, en el lago de Choclococha, se contaba que un antepasado construyó un canal subterráneo que llevó el agua a los pueblos aledaños (Sherbondy 1982, 10). También se menciona que los Incas, en momentos críticos, reorganizaron sus tierras y aguas a lo largo de su historia. Una de estas reorganizaciones se efectuó con base en la sistematización en los ceques. Por lo tanto, las fuentes de agua llegaron a ser huacas principales y fueron incorporados al sistema de ceques como tal.

Por otro lado, esta organización generó un conjunto de especialistas en la repartición del agua que no llegó a burocratizarse, ya que las poblaciones manejaban con gran autonomía su obtención y distribución. No obstante, para
Sherbondy $(1982,12)$, el agua era un elemento original del cosmos que representaba la esencia de la vida misma y el sol se subordinaba a ella. En resumen, se puede decir que los pueblos andinos antiguos no solo poseían los conocimientos prácticos de la hidrología y desarrollaron técnicas para utilizar las aguas subterráneas y de superficie, sino que también elaboraron una cosmología basada en estos conocimientos que era útil para expresar conceptos de etnicidad y de unidad política (Sherbondy 1982, 13). Por su lado, otro teórico como Karl Wittfogel, en su estudio sobre las sociedades hidráulicas, planteaba, en la década de 1950, como factor de estratificación social y de urbanismo, que el control hidráulico se basaba en una planificada "burocracia hidráulica" auspiciada por el gobierno imperante. Esta tesis, para los Andes, no es aplicable, ya que, por ejemplo, los centros ceremoniales y las formas urbanas precedieron a las obras de irrigación en gran escala.

\section{Abastecimiento de AgUa en Lima}

\section{Agua potable}

Las poblaciones prehispánicas extraían agua potable del río Rímac, en una época en que aún eran saludables. La fundación de la ciudad de Lima (18 de enero de 1535) trajo consigo, como es obvio, un gran impacto en el ordenamiento previo; en lo sucesivo, el abastecimiento ya no pudo efectuarse de forma directa en el mismo río, debido a que se presentaron enfermedades achacadas a la contaminación ambiental, como el catarro, el garrotillo y el asma, por lo que tuvo que buscarse un manantial en las inmediaciones (Durán 1994, 96). Como es de notar, la alteración que acarreó el establecimiento de los españoles modificó grandemente la obtención del recurso hídrico.

Las nuevas leyes dictadas por el orden imperante se tradujeron en ordenanzas: así, recién en 1552 las autoridades se preocuparon por extraer agua de los manantiales en la zona de Cacahuasi (al este de Lima) y, a partir de 1560, se realizaron trabajos para colocar nuevos conductos 
de agua en la ciudad (Gutiérrez, 2005, 116). El camino que seguían los puquíos comenzaba en la Caja Real, que era un edificio que encerraba entre paredes los manantiales, desde donde se iniciaba un acueducto o canal de ladrillo y cal abovedado. Este se transformaba en la ciudad en una matriz principal formada por tubos de barro cocido, que terminaba en la Plaza Mayor (Sedapal 1997,10). Con el fin de no interrumpir la construcción —-situación que haría perder el trabajo realizado-, se procuró el dinero necesario, creándose un impuesto a la carne que fue la primera sisa que introdujeron las autoridades en la ciudad (Middendorf 1974, 143). Así pues, la plaza consolidó su importancia al convertirse en el punto central del sistema colonial hidráulico de Lima (Gutiérrez 2005, 115). Esta obra se consolidó en el gobierno del virrey Toledo, cuando por primera vez empezó a brotar agua de la pileta (Bromley y Barbagelata 1945, 41).

También el agua era distribuida entre las piletas de los conventos, los cuales la proveían en pilones al vecindario (Bromley y Barbagelata 1945, 9). Entre las instituciones que recibieron agua por primera vez tenemos: el Convento de San Francisco, el Convento de Santo Domingo, el Tribunal de la Santa Inquisición (Fig. 1 y Fig.
2), el Monasterio de la Concepción, la Iglesia de San Pedro, el Convento de San Agustín, el Convento de La Merced, la Plazuela de San Marcelo, la Alcaldía, la Catedral y el actual Palacio de Gobierno.

Como dato adicional, se puede mencionar que no existía restricción al consumo y el agua podía mantenerse corriente todo el día, como sucedía en las pilas y piletas públicas (Bromley y Barbagelata 1945, 42). Ahora bien, el frágil material de las cañerías ocasionaba que en muchos lugares se saliera el agua, lo que aumentaba la humedad del suelo y asimismo, que el agua en las cañerías se contaminara por las acequias de la ciudad que se extendían en sus proximidades (Middendorf, 1974:416). En otras partes de la ciudad Middendorf observaba: "El agua que sale del matadero es conducida a la parte más cercana del río. Allí está ahora la reunión de las bandadas de gallinazos, las negras y repugnantes aves de rapiña, que antes, cuando todavía existían acequias abiertas en medio de las calles, buscaban y encontraban sus alimentos en la ciudad. Por centenares merodean en las aguas llenas de sangre y se disputan los pequeños desperdicios de carne" (Middendorf, 1974: 42).
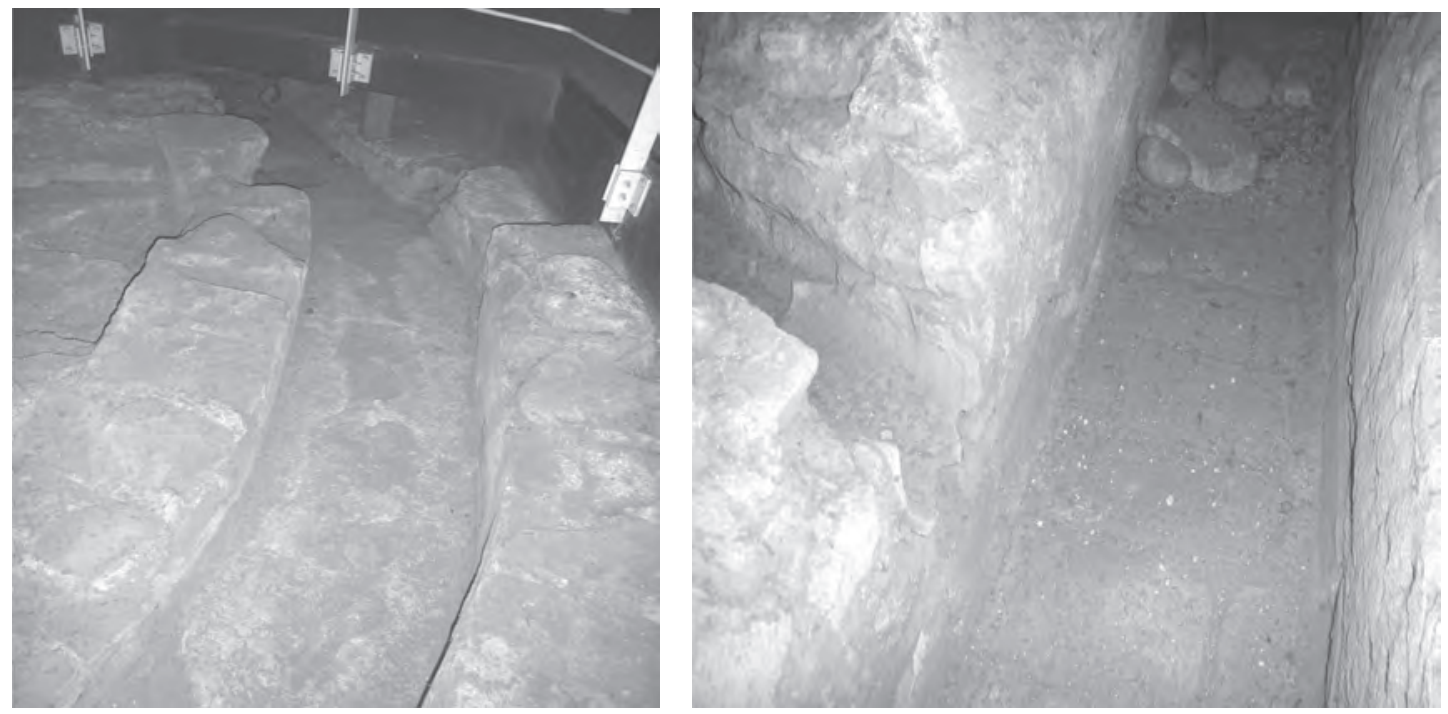

Figuras 1 y 2. Acueductos para el agua potable en La Santa Inquisición. Fotografías de Paul Pérez (2010). 
Debido a que la cantidad de habitantes de la ciudad que tenían una conexión de agua hacia sus casas era muy menor, se había implementado un sistema de compra de agua, sobre todo a las familia adineradas, así pues la venta de agua era encargada a los aguadores, que eran generalmente negros libertos, y que traían agua de otras vertientes como Piedra Liza, montado en sus asnos, ofrecían el agua en dos grandes cántaros de barro (Calderón, 2000: 108).

Recién en 1856 las cañerías de barro serían cambiadas por las de metal. En efecto pues ochenta cañerías subterráneas traían, en los últimos días de la colonia, el agua para el servicio urbano (Di Doménico, 1945:50). En época republicana se sistematizó este servicio a través de distintas obras de captación que fueron ampliadas siguiendo las exigencias de la población, ya que esta había crecido más allá de lo que eran hasta entonces las murallas de Lima de manera que se buscó a través de diversos proyectos la captación del agua en lagunas que ya no estaban cerca de la actual Atarjea. Se pensaba entonces que las posibilidades de captación aparte del mismo río Rímac podían ser conseguidas en las alturas. No obstante se siguió manteniendo a la atarjea como el punto de captación más cercano a la ciudad.

\section{Aguas De REgadío}

En cuanto a las aguas de regadío podemos decir que las poblaciones que encontraron los españoles a su llegada, como ya se dijo, utilizaban el sistema de acequias. Los datos etnohistóricos permiten tener una idea de cómo fue la organización política de los pueblos costeños:

"El valle bajo y medio se hallaba regado por extensos canales que partían del río y se extendían por la planicie aluvial" (Mejía, 1998: 6).

En efecto María Rostworowski señala que:

"Estas poblaciones estaban divididas por señoríos principales. En el valle del Rímac se asentaban los de Lima, Sulco, Guatca y Malanca.
"Cada cacicazgo estuvo relacionado a una acequia principal, de la que se desprendían numerosos ramales con las que regaban sus tierras. En época colonial estas acequias fueron derivadas a las huertas de la nueva ciudad, aunque en líneas generales se mantuvo el sistema hidráulico antiguo" (Rostworowski, 1978:53).

Al parecer esto último indicaría que las poblaciones estuvieron organizadas en torno a los canales, en lo que correspondería a su mantenimiento (limpieza) y control (administración). Las divisiones por medio de acequias debieron de funcionar también para los señoríos de Lati, cuya acequia principal sería el Surco y cuya bocatoma se encontraría actualmente en el puente Huachipa y atraviesa los distritos de Huachipa, Ate - Vitarte, La Molina y Surco (Mejía,1998:6). Este canal, suponemos por la cercanía, mantendría alguna relación con el sitio arqueológico de Puruchuco. Más tarde en los alrededores los españoles fundaron en Lati una reducción indígena y obligaron a los habitantes de las aldeas vecinas a establecerse en él. El nuevo pueblo recibió el nombre de Santa Cruz, conocido posteriormente como Ate (Rostworowski, 1978:54).

En cuanto al señorío de Sulco que comprende los distritos de Surco, Chorrillos, Barranco, Surquillo y parte de Miraflores (Rostworowski, 1978:55) presentaba el mismo orden, es decir se supeditaba al canal de Surco que termina su recorrido en el actual distrito de Chorrillos.

Estos antecedentes sobre la ocupación previa de la futura ciudad, nos dan un marco contextual sobre los asentamientos prehispánicos en cuanto a la utilización del agua que previamente se tenía. Mas adelante las nuevas leyes emanadas por gobierno español estuvieron encaminadas a la creación de autoridades para el control de aguas. Es decir si existía un control previo de las acequias por las mismas poblaciones indígenas estas fueron reemplazadas por las nuevas autoridades denominando así a los Jueces de Agua. 


\section{Canal de Huatica}

El Canal o río de Huatica fue una de las grandes acequias principales que surgieron en el valle del Rímac y que extrayendo agua del río del mismo nombre se originaba en las laderas del cerro Coscaya, a partir de la constitución de su suelo, plagado de manantiales de procedencia subterránea, llamados vulgarmente "ojos de agua" - en lengua vernácula - puquíos. Esas tierras, al menos hasta finales del siglo XVIII, eran conocidas como "la Sabana" (Flores - Zúñiga, 2008:63).

No obstante el dato anotado el punto de captación del canal, y es muy probable, haya cambiado con el paso del tiempo, ya que en los planos de periodos coloniales se hace notar que su origen se encontraría en los muladares de Martinete.

Al encontrarse los españoles con un sistema de acequias utilizado para el riego de cultivos suponemos que también encontraron una equilibrada y excelente capacidad de producción de cultivos, al menos para la cantidad de personas que se asentaban en el valle. En cuanto a su distribución en la colonia, que recién se instalaba, Cobo nos dice:

"Que la mayor parte de las acequias se derivan de una muy grande, que por entrar en la ciudad por junto al Monasterio de Santa Clara, la llamaron de este nombre, la cual no embargante que cuando se fundó esta ciudad caía fuera de su traza". (Cobo, 1956:314)

Es importante este dato, ya que se determina de esta manera que este canal fue adecuado posteriormente con el objetivo de atravesar las huertas y jardines del nuevo asentamiento que se instalaba en Lima. Y esta adecuación se llevó a cabo por los "nuevos vecinos", quienes realizaron excavaciones de acequias para llevar agua a sus solares, obras que fueron una de las primeras actividades reguladas por el Cabildo. Por ejemplo en 1535 se dispuso que los canales se hicieran a vista del alcalde y regidores, quienes debían decidir su trazo, con entrada y salida para otros solares, y que las partes que atravesaban las calles debían cubrirse (Gutiérrez, 2005:116).

En el plano rural, entre los fundos que el Canal de Huatica irrigaba, citaremos en forma resumida la relación que se desarrolla de la siguiente manera (Flores - Zúñiga, 2008:138):

Matamandinga: Que comprendía desde el Jirón de la Unión y la Plaza Miguel Grau. Para una ubicación espacial este fundo se encontraría situado en el actual Parque de la Exposición en donde se encuentra el Museo de Arte.

Cabezas, Gárate o la Victoria: Constituía la actual Avenida 28 de julio, en su intersección con el Paseo de la República. Forma gran parte del actual distrito de La Victoria.

San Martín: Situado al oeste de la Victoria que fuera de propiedad jesuita. Limitaba entre las actuales avenidas Brasil, Plaza Bolognesi, y las dos o tres primeras cuadras del Paseo Colón. Por el sur existía un estanque que constituía su frontera con Santa Beatriz.

Santa Beatriz: Se convirtió en una próspera hacienda cañaveral de propiedad jesuita. Estaba situado entre las avenidas 28 de julio y Bergase Du Petit Thouars. Y el centro de la hacienda debió de extenderse en el actual Parque de la Reserva.

Matalechuzas, Matalechucitas o Villablanca: Jesús María Se situaba en los linderos del actual distrito Jesús María, por lo que este fundo colindaba con las haciendas de Orrantia y Lobatón (actual distrito de Lince).

San Nicolás o Ibarrola: Se extendía entre la Avenida Arequipa, la Avenida Arenales y las vecindades del actual complejo arquitectónico del Seguro Social Peruano.

Luján, Gurmendi o Lobatón: Corresponde a parte del actual distrito de Lince.

Entre otros fundos tenemos a: El Cármen, Santa Teresa o Lince, Olavarrieta, Zumarán, Villar o San Isidro, San José de Huatica u Orrantia, Santa Cruz y la Chacarilla. 
En la actualidad aún se siguen utilizando las aguas de acequia para irrigar los jardines y parques de muchos distritos de la capital, por citar un caso podemos hablar de Jesús María en cuya jurisdicción se encuentra el Campo de Marte, siendo unos de los pocos pulmones verdes de la gran capital, utiliza el agua de acequias que se encuentran ocultas debajo del asfalto al paso de las avenidas Salaverry y 28 de julio.

\section{Aspecto económico}

Ya se ha discutido ampliamente en los capítulos anteriores sobre el rol importante que tuvo en la agricultura el canal de Huatica. Sin embargo este ámbito no sólo se enmarco en este punto, ya que en su recorrido, sobre todo en el centro de la Ciudad de Lima, intervino a manera de fuerza hidráulica para los molinos y las maquinas de acuñación de monedas. Así pues Cobo mencionaba que el Huatica:

"Movía tres o cuatro ruedas de molinos de pan y que había en su curso dentro de la ciudad cinco molinos, de a tres o cuatro pies cada uno, y hay piedras que muelen a más de cien hanegas de trigo entre día y noche". (Cobo, 1956:314)

Este dato nos afirma la importancia económica que tuvo este canal al ser el responsable de dar energía a los primigenios molinos. Anotamos a continuación según Flores - Zúñiga, F. (2008:101) la relación de molinos a los cuales daba fuerza hidráulica:

- El de Pampa

- El del medio

- El de Martinete

- El de Santa Clara (cuya sede, que es un edificio situado en jirón Ancash)

- El de San Pedro Nolasco (entre los jirones Andahuaylas y Cuzco)

- El de Santa Catalina

Por otro lado La Casa de la Moneda fundada en 1565 mediante la Real Cédula del monarca Felipe II surge con el objetivo explícito de emitir monedas al Virreinato del Perú, ya que esta era desorganizada, lo cual creaba un real caos en el sistema colonial que se adecuaba a las nuevas tierras. Es por esta razón que con la apertura de la sede se adquirirán máquinas especiales para la acuñación de monedas, no obstante el trabajo utilizaba fuerza humana para el propósito inicial. Es recién a finales del siglo XVIII cuando se dejó de lado la técnica del martillado para pasar a otro mecanismo en base a los "volantes" cuya utilidad hizo que el trabajo se agilice (Banco Central de Reserva del Perú, sin año: 16), no obstante más adelante la elaboración se agilizaría más todavía cuando esta casa adecuó el Canal de Huatica, utilizando así su fuerza hidráulica para mover las maquinarias para acuñación.

\section{Salubridad e higiene}

En tiempos coloniales este fue un tema que desde siempre preocupó a las autoridades al punto de realizar reformas y disposiciones a favor de la salubridad. No obstante no siempre lograron contener el avance de las enfermedades convirtiéndose en un gran problema social. Una de las primeras medidas que se ejecutó fue la de prohibir el beber el agua del río Rímac, ya que estas no se encontraban en las mismas condiciones en que las encontraron los primeros españoles (Lossio, 2003:26). Por su lado el crecimiento poblacional había ocasionado que en pocos años se contaminen sus riveras. A esto había que sumarle la presencia de enfermedades estomacales, catarro, disentería, etc. Pero así como aparecieron enfermedades, también se fundaron los primeros hospitales, como el de San Andrés (actualmente ubicado entre el Jirón Huallaga y la Plaza Italia) que trataron de reducir estos males.

No obstante nuevamente las molestias seguirían hasta que en 1785 se comienza a suprimir las acequias y sus benéficos resultados se comenzaron a sentirse en la estética urbana y en el menor numero de enfermos registrados en los hospitales en los años que siguieron esta reforma (Bromley y Barbagelata, 1945:92). En palabras 
generales la sensación de insalubridad que se vivía con las acequias debió de haber sido un gran reto para las autoridades, así nos lo recuerda Bromley y Barbagelata en 1857:

"Nada más desagradable a la vista, más repugnante al olfato y más perjudicial a la salud que esas grietas irregulares, que conduciendo en más o menos abundancia un líquido semiespeso tan variado en sus matices como en sus olores, recorren todos los puntos de la capital con el nombre de acequias. Destinadas a ser para las poblaciones lo que los ríos para los campos, es decir, la vida y la alegría, se han convertido entre nosotros en poderosos agentes de disgusto y de enfermedades. Son la causa principal de las terribles intermitentes, de los tabardillos, de las graves desinterías y de otras enfermedades que diezman la población, especialmente en otoño". (Bromley y Barbagelata, 1945:93)

Viendo lo antes dicho las primeras obras a ejecutarse para resolver este problema fue el crear un sistema de alcantarillado que pudiera ser enfocado en la evacuación de los detritus orgánicos y ser utilizado exclusivamente por conductos denominados "albañales" que no son más que cañerías que dan salida a las aguas inmundas (Real Academia Española, 2005:60) y que podríamos considerarlos como los primeros sistemas de desagüe limeño. Es decir dejar de lado el antiguo sistema de acequias como el Huatica y sus canales secundarios que eran utilizados desde tempranos tiempos coloniales como los principales colectores, ya que se pensaba que éste (en el caso del Huatica) podía depurar a lo largo de su recorrido el detritus orgánico.

Las condiciones en que vivían los limeños en cuanto a la sanidad doméstica se sumaban a los grandes problemas de salubridad e higiene que ya se tenía en las calles, debido a que debajo de las casas atravesaban los canales, así pues estas construcciones tenían pisos de madera, lo cuartos de ellas servían de dormitorio, eran oscuras y sin ventilación. Las personas que vivían allí estaban expuestas al recargado vapor acuoso y miasmas que atravesaban las delgadas maderas que constituían el mismo piso (Ribeyro, 1912:10). El término "miasma" era aludido al efluvio maligno, que según se creía, desprendían cuerpos enfermos, materias corruptas o aguas estancadas (Real Academia Española, 2005:1017).

Recién en 1859 se instalaron los primeros sistemas de albañales en la Calle de las Mantas (hoy jirón Callao) en una longitud de $117 \mathrm{~m}$. que fueron reanudados en 1862 para más tarde mediante una ordenanza en 1869 se planteara la contribución económica del vecindario mediante la cuota de 10 pesos por vara lineal de canalización (Bromley y Barbagelata, 1945:95). Estas modificaciones en cuanto a la instalación de canales exclusivos se debieron a la aparición de enfermedades como la peste bubónica o la fiebre amarilla. En 1902 se presenta un informe sobre la canalización de los albañales y se proponen tomar medidas esto debido a que la fiebre tifoidea que había aparecido estaba causando mortandad culpando a la mala canalización ejecutada en obras anteriores. Recién será en 1916 cuando se instalen tuberías de gress cerámica, sin embargo no se subsanó el problema de evacuar los albañales a los campos de cultivo (Matos y Matos, 1990:26). Esto se daba porque el sistema de albañales se seguía manteniendo conectado al de las acequias principales como el Huatica cuyas aguas eran usadas para el lavado de estas tuberías que después volverían nuevamente al canal principal. Actualmente las acequias que atravesaban el Centro de Lima han sido eliminadas, ya que fueron cambiados por conductos exclusivamente para la evacuación de desagües. Finalmente el canal de Huatica, que fue suspendido de uso al menos en la parte del Centro de Lima, nos recuerda que fueron las poblaciones indígenas las que supieron aprovechar el recurso hídrico antes de la llegada de los españoles. 


\section{Evicencias}

Gracias al plano del recorrido realizado por Ribeyro en 1912, podemos describir las calles por donde hubo de atravesar dicho canal, sin embargo por motivos didácticos citaremos el nombre de las calles actuales sólo para el actual Centro Histórico de Lima:

- Empezaba la toma en Martinete (actual rivera del río Rímac)

- Proseguía por el jirón Amazonas cruzando la calle Maynas y es en esta intersección donde se ocultaba bajo las viviendas.

- Continua por el jirón Huánuco hasta llegar a Ancash cruzando el jirón Huanta y Paruro debajo de las viviendas hasta llega a la Casa de la Moneda.

- De la Casa de la Moneda cruzaba por debajo del actual Colegio Mercedes Cabello hasta nuevamente salir por el jirón Andahuaylas para cruzarlo e ir hacia el Mercado Central.
- Del Mercado Central salía cruzando el jirón Ucayali para luego volver a jirón Andahuaylas hasta la intersección con jirón Cuzco donde de dividía en dos: un brazo iba por Mesa Redonda y el otro seguía por Andahuaylas para nuevamente encontrarse en este mismo jirón.

- Todo el recorrido seguía el jirón Andahuaylas hasta cruzar el Cuartel Santa Catalina, donde se introducía para luego retomar el mencionado jirón y cruzar la Avenida Grau en donde se daba paso al actual distrito de La Victoria por el lado sur, así como a Jesús María por el oeste.

- El gran recorrido recién terminaba en lo que era los campos de cultivo situados en el actual distrito de Miraflores en su dimensión más larga aproximadamente.

A continuación presentamos algunos lugares (Fig. 3,4 y 5) donde se logró y/o se ha logrado ver al canal:

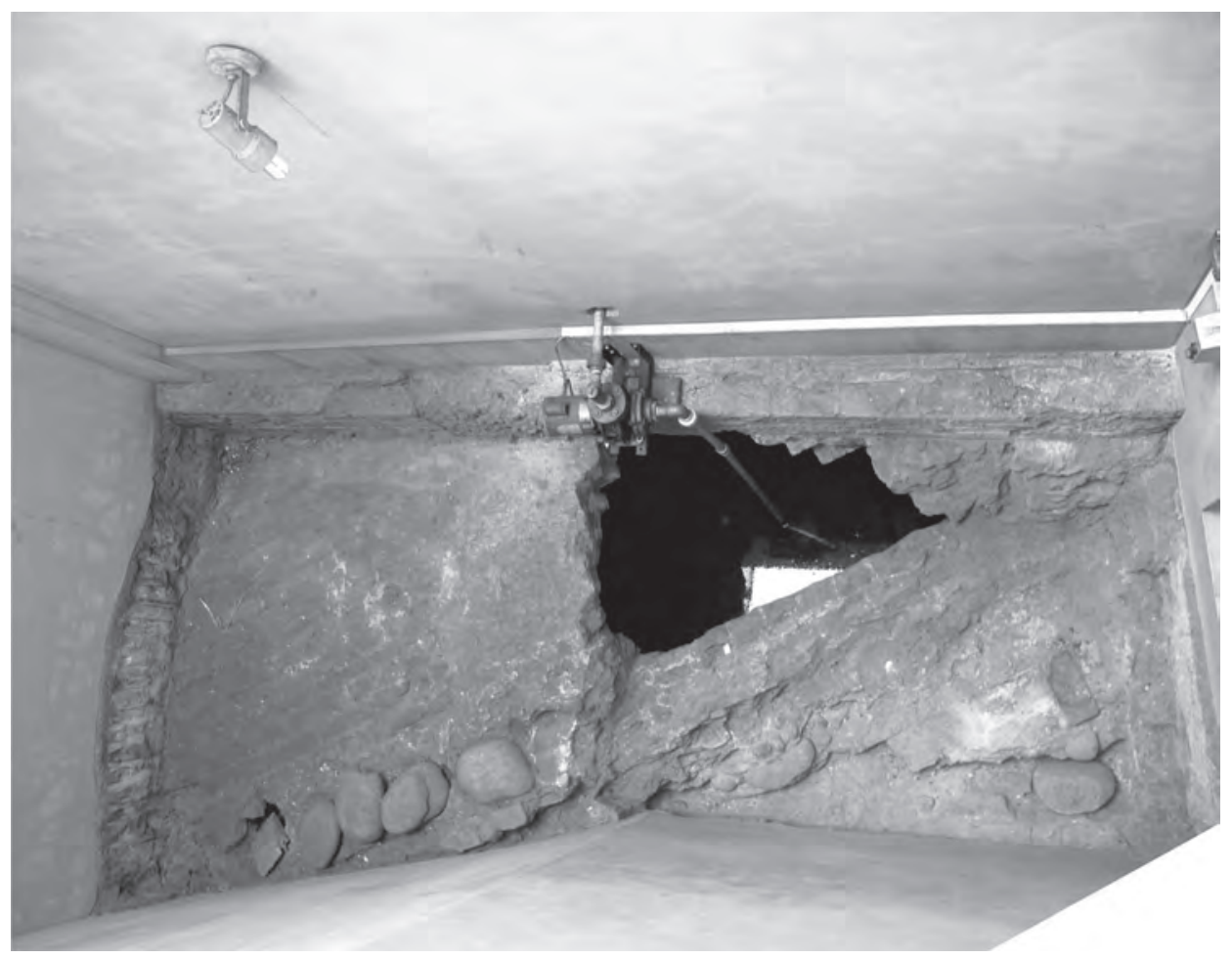

Figura 3. Museo Numismático del Perú. Fotografía de Paul Pérez (2008). 


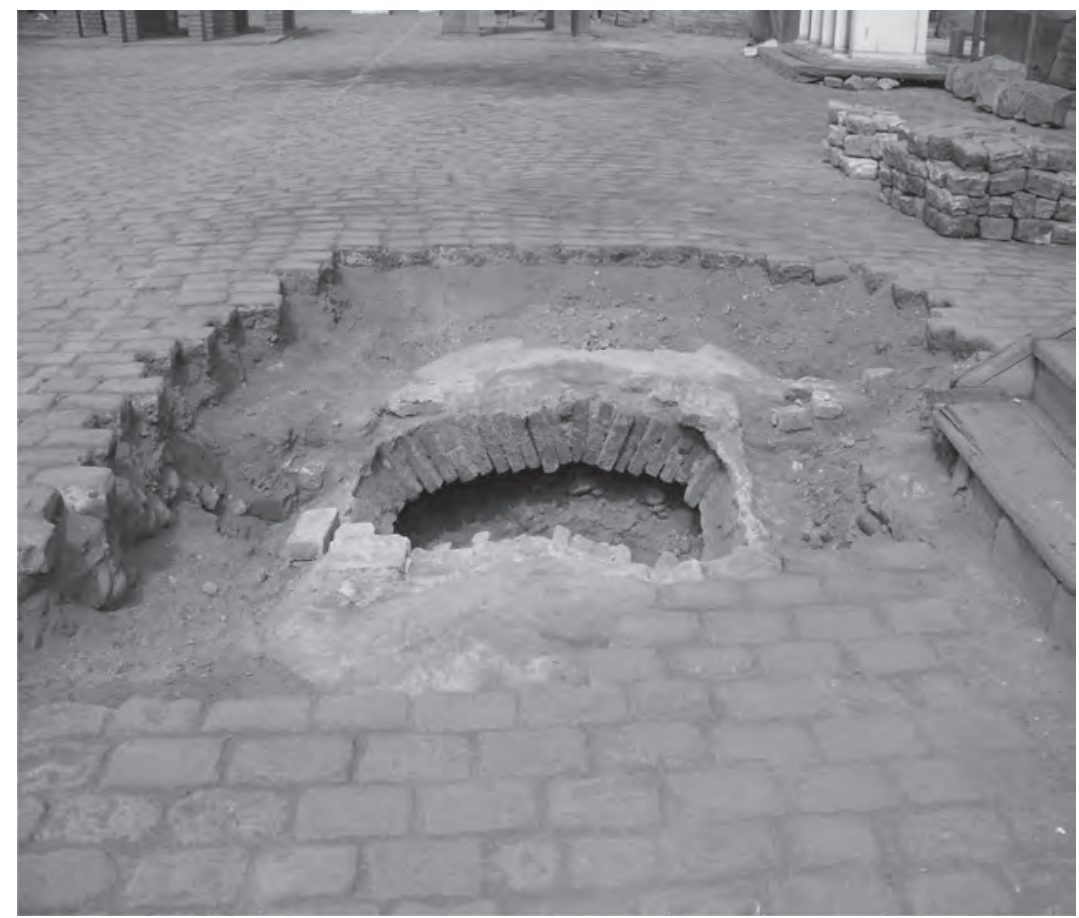

Figura 4. Cuartel de Santa Catalina. Fotografía de Antonio Coello (2008).

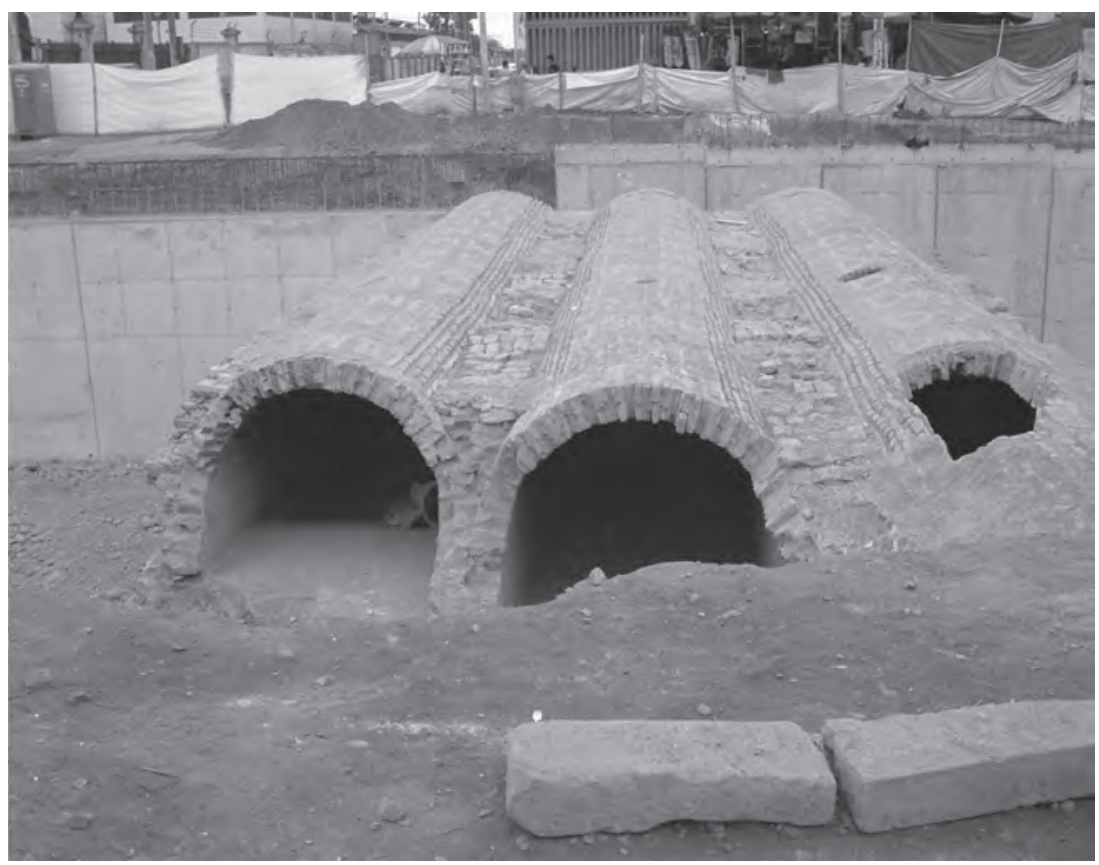

Figura 5. Avenida Grau. Fotografía de Antonio Coello (2005). 


\section{CONCLUSIONES}

- La irrigación prehispánica fue el primer paso que consolidó el equilibrio entre el poblador y los recursos de subsistencia que pudo producir gracias a los sistemas de canales.

- Los españoles sustituyeron el poder y control en el valle en cuanto al regadío corresponde, ya que si en épocas prehispánicas se tenía una administración desde el Curaca, en la colonia se ejercería el control desde el Juez de Aguas.

- El canal de Huatica sirvió en gran parte para la irrigación de los actuales distritos: de Cercado de Lima, La Victoria, Lince y San Isidro, ya que estos eran fundos cuyos propietarios fueron españoles. Gracias al complejo sistemas de canales secundarios que salían de éste.

- El agua potable fue extraída desde los manantiales del actual distrito de Ate Vitarte, lugar que hoy ocupa La Atarjea y que produjo todo un cambio social, ya que, en parte se trató de mejorar la salud con agua utilizada exclusivamente como potable.

- Los problemas de salubridad e higiene fueron en tiempos coloniales y hasta republicanos de repercusión social, debido al mal manejo que se le dio a las acequias principales y secundarias. El Huatica se convirtió en un gran colector de aguas servidas. Sin embargo siempre se tuvo conciencia de que los malos hábitos de higiene se concentraban en el seguir utilizando las acequias como desagües.

- La importancia del canal de Huatica no sólo radicó en el uso de sus aguas para el agro o como depurador del detritus orgánico, ya que su potencia hidráulica fue utilizada para dar movimiento a los molinos y máquinas de acuñación en la Casa de la Moneda.

\section{BiBliografíA}

Agusto, Santiago.

1984 Lima Prehispánica. Lima, Municipalidad Metropolitana de Lima
Banco Central de Reserva del Perú

s/f Catálogo del Museo numismático del Perú. Lima

Biblioteca de Autores Españoles

1956 Obras del P. Bernabé Cobo. Tomo II. 1a․ ed. Madrid

Bromley, Juan y José Barbagelata

1945 Evolución urbana de Lima. Lima. Editorial Lumen.

Calderón, Glady s

2000 La casa limeña, espacios habitados. Lima Perú. Siklos.

Capuñay, Manuel

1957 La irrigación en el Perú. Tesis de Doctorado, Universidad Nacional Mayor de San Marcos.

Cárdenas, Mario

1989 La población aborigen del valle de Lima en el S. XVI. Lima, CONCYTEC.

Deza, R. Jaime

2005 El agua de los Incas: Sistema de riego en el Perú prehispánico. Lima. Universidad Alas Peruanas

Di Doménico S, M. Haydeé

1945 La fuente de la Plaza Mayor de Lima. Tesis de bachiller. UNMSM

Durán, M. Antonia

1994 Lima en el siglo XVII. Sevilla, Excma. Diputación de Sevilla.

Flores-Zúñiga, Fernando

2008 Haciendas y pueblos de Lima: Historia del valle del Rímac (de sus orígenes al siglo XX). 1 ${ }^{\mathrm{a}}$. ed. Tomo I. Fondo Editorial del Congreso de la República

Gonzáles C., Gabriela

1998 Lima antigua (10.000 a.C. a 1532). 1a․ ed. Lima, Perú Seminario de Historia Rural Andina - UNMSM.

Gutiérrez, A, L.

2005 Lima en el siglo XVI. 1a. ed. Lima - Perú. PUCP - Instituto Riva-Agüero.

Lossio, Jorge.

2003 Acequias y gallinazos, salud ambiental en Lima del siglo XIX. 1․a ed. Lima. IEP

Matos M., José y Rubén Matos L.

1990 Aguas residuales, agricultura y alimentación en la gran Lima. Lima. CONCYTEC. 
Mejía H, L. Felipe

1998 "El sistema hidráulico de Lima prehispánica: Etapas constructivas del Canal de Ate". Boletín del Museo de Arqueología y Antropología UNMSM. № 4, Año 1, p. $6-7$

Middendorf, Ernst. W.

1974 Perú, observaciones y estudios del país y sus habitantes durante una permanencia de 25 años. Tomo I - II. 1 $\stackrel{\text { a }}{\text {. ed. Lima. }}$ UNMSM

Museo de Aqueología y Antropología-UNMSM

1999 Cuadernos de investigación del archivo Tello: arqueología del valle de Lima № $11^{\text {a }}$. ed. Lima

Parker, S. David

2002 "Civilizando la Ciudad de Los Reyes: higiene y vivienda en Lima, 1890 - 1920" En: Norma, Ed. Entre médicos y curanderos (Cultura, historia y enfermedad en la América Latina moderna), Argentina. Grupo Editorial Norma p. 107 - 150

PEISA ED.

2004 Atlas Regional del Perú-Lima 1a. ed. Tomo 16 Lima
Real Academia Española

2005 Diccionario de la Lengua Española. Tomo II y XIII 20a․ Lima. Espasa.

Regal, M. Alberto

2005 Los trabajos hidráulicos del inca en el antiguo Perú. 2a. ed. Lima. INC

Ribeyro, Julio

1912 Saneamiento del río Huatica Lima - Perú. Litografía y Tipología

1934 Saneamiento de Lima. Lima. Imprenta Gil

Rostworowski, Maria

1978 Señoríos indígenas de Lima y Canta. 1a․ ed. Lima. IEP.

\section{SEDAPAL}

1997 Historia del abastecimiento de agua potable de Lima, 1535-1996, 1a. ed. Lima - Perú. Ministerio de la Presidencia

Sherbondy, Jeanette

1982 "El regadío, los lagos y los mitos de origen”. En: IPA, Allpanchis. Cuzco - Perú Año XII, Vol. XVII. № 20 p. 3-32

Villafana Juan A.

1986 Sistemas hidráulicos incas. 1ª ed. Lima. Lluvia Editores 